\title{
Efeitos Econômicos da Duplicação da BR 116: uma análise para a Mesorregião Sudeste do Rio Grande do Sul
}

\author{
Rodrigo da Rocha Gonçalves \\ Universidade Federal do Rio Grande - Rio Grande - Rio Grande do Sul -Brasil \\ ORCID: https://orcid.org/0000-0003-0596-5576 \\ Gabrielito Menezes \\ Universidade Federal de Pelotas - Pelotas - Rio Grande do Sul - Brasil \\ ORCID: https://orcid.org/0000-0001-7649-5132
}

\section{Resumo}

O presente artigo tem por objetivo estimar uma Matriz Insumo Produto (MIP) para a Mesorregião Sudeste do Rio Grande do Sul, buscando analisar os impactos econômicos da duplicação do trecho sul da BR 116 de curto e longo prazo, considerando a redução dos custos de transporte. Os resultados evidenciam que a economia da região está fortemente ligada as cadeias produtivas da pecuária e alimentos; produção de florestas e a indústria da construção naval e a construção. No tocante aos efeitos da duplicação da BR 116, os setores mais afetados foram o setor de construção e seus principais fornecedores. Por sua vez, os resultados para a redução das margens de transporte rodoviário demonstraram que os setores de outros produtos alimentares; peças e acessórios para veículos automotores; fabricação de equipamentos eletrônicos e informática; artigos de borracha e plásticos; produtos farmoquímicos e farmacêuticos; máquinas e equipamentos; agricultura, silvicultura e outros equipamentos para transporte sofreram os maiores incrementos na produção e no valor adicionado.

Palavras-chave: Infraestrutura. Matriz Insumo Produto. Mesorregião Sudeste.

\section{Economic Effects of BR 116 Duplication: an analysis for the Southeast Meso-region of Rio Grande do Sul}

\section{Abstract}

The present paper aims to estimate a Input Output Matrix (MIP) for the Southeast Mesoregion of Rio Grande do Sul, seeking to analyze the economic impacts of the duplication of the southern section of BR 116 in the short and long term, considering the reduction of transportation costs. The results indicated that the economy of the region is strongly linked to the productive chains of livestock and food; forestry and shipbuilding and construction. With regard to the results of the duplication of BR 116, during the construction period the sectors most affected were the construction sector and its main suppliers. In turn, the results for the reduction of road transport margins have shown that other food sectors sectors; parts and accessories for motor vehicles; manufacture of 
electronic and computer equipment; rubber and plastic articles; pharmacochemical and pharmaceutical products; machines and equipment; agriculture, forestry and other transportation equipment suffered the greatest increases in production and value added.

Keywords: Infrastructure. Input-Output Matrix. Southeast Meso-region.

\section{Efectos Económicos de la Duplicación de la BR 116: un análisis para la Mesorregión Sudeste de Rio Grande do Sul}

\section{Resumen}

El presente artículo tiene por objetivo estimar una Matriz Insumo Producto (MIP) para la Mesorregión Sudeste de Rio Grande do Sul, para analizar los impactos económicos de la duplicación del tramo sur de la BR 116 a corto y largo plazo, considerando la reducción de los costos de transporte. Los resultados evidencian que la economía de la región está fuertemente ligada a las cadenas productivas de la ganadería y alimentos; producción de bosques y la industria de la construcción naval y la construcción. En lo que se refiere a los efectos de la duplicación de la BR 116, los sectores más afectados fueron el sector de construcción y sus principales proveedores. Por su parte, los resultados para la reducción de los márgenes de transporte por carretera demostraron que los sectores otros productos alimenticios; piezas y accesorios para vehículos automotores; fabricación de equipos electrónicos e informática; artículos de caucho y plásticos; productos farmacéuticos y farmacéuticos; máquinas y equipos; agricultura, silvicultura y otros equipos para el transporte sufrieron los mayores incrementos en la producción y en el valor agregado.

Palabras clave: Infraestructura. Matriz Insumo Producto. Mesorregión Sudeste.

\section{Introdução}

O propósito deste trabalho é avaliar os impactos econômicos da duplicação da BR 116, partindo da estimação de uma Matriz Insumo Produto (MIP) para a Mesorregião Sudeste do Rio Grande do Sul (RS) com abertura dos setores de transporte de cargas e a desagregação das margens de transporte e calculando: i) os multiplicadores de impactos de produção, valor adicionado, emprego e os índices de ligação para frente e para trás e ii) os efeitos econômicos na fase de construção e, posteriormente, a diminuição da margem de transporte rodoviário gerada por reduções no tempo de viagem e no custo do frete.

O Rio Grande do Sul possui sete mesorregiões, as quais apresentam diferenças produtivas oriundas de características demográficas, sociais, econômicas e ambientais. A Mesorregião Sudeste, localizada na região Sul do estado, pode ser considerada a quinta economia estadual, ficando atrás das mesorregiões Metropolitana, Noroeste, Nordeste e Ocidental na participação no Produto Interno Bruto (PIB) e na geração de riqueza.

A mesorregião é importante por possuir o porto de Rio Grande, único porto Marítimo estadual, pelo qual segundos dados da FEE (2016) passam em torno de $80 \%$ das exportações do RS para outros países. O porto possui conexão com outras mesorregiões por hidrovias, ferrovias e rodovia. Todavia, a grande concentração de cargas pelo sistema rodoviário configura-se um dos principais gargalos do terminal, principalmente em virtude da principal rodovia - BR 116 - não possuir faixa dupla.

A estimação de uma MIP para a mesorregião torna-se relevante na busca de encontrar setores que impulsionem o desenvolvimento regional, sobretudo visando minimizar os efeitos da redução da atividade do setor naval. Além disso, a 
mensuração da MIP contribui para avaliação quantitativa de melhorias na logística da região, buscando a consolidação do Porto de Rio Grande na região Sul do Brasil.

A avaliação de impactos econômicos decorrentes da melhoria na infraestrutura de transporte é amplamente estudada na literatura econômica, principalmente, relacionando impactos de investimentos em infraestrutura no desenvolvimento econômico e regional com a utilização de diversas metodologias. Porém, a literatura empírica concentra-se na utilização de modelos econométricos e modelos de equilíbrio geral computável. Sendo esses últimos, a metodologia mais apropriada na concepção de diversos autores, tais como, Brocker (2000); Robson e Dixit (2015) e Araújo e Guilhoto (2008).

O custo de transporte é considerado parte fundamental na formação do preço dos bens. Sendo assim, à medida que a oferta de infraestrutura melhora, reduz o custo de transporte. Com isso, diminui a utilização de margens de transporte gerando a realocação de recursos para outros setores (HADDAD, 2004). A maior parte da literatura empírica sobre melhorias em transporte surge da concepção teórica dos modelos de localização desenvolvidos por Von Thünen (1826); Weber (1909); Löch (1954); Isard (1956) e Christaller (1966). Tais modelos analisam os fatores que influenciam as decisões das atividades socioeconômicas (agrícolas, industriais e comerciais), devido ao desenvolvimento na infraestrutura relacionada a transporte.

Recentemente, os modelos da Nova Geografia econômica têm contribuído com a temática, Krugman (1991) e Venables (1996) estudam os custos de transporte e sua relação com a distribuição espacial das firmas, assumindo as hipóteses de retornos crescentes de escala, concorrência imperfeita e considerado os aspectos da teoria de equilíbrio geral.

Para atender os objetivos citados, este artigo está organizado em cinco seções, além desta introdução. Apresentamos a mesorregião Sudeste do Rio Grande na seção dois, enfatizando a importância da BR 116 para a região. Na terceira seção, realizamos uma revisão de literatura sobre MIP, ressaltando as principais técnicas de regionalização da mesma. Na quarta seção, demonstramos os aspectos metodológicos, bem como apresentação e discussão dos resultados. Finalmente, apresentamos as considerações finais na quinta seção.

\section{A Mesorregião Sudeste e a duplicação da BR 116}

O Rio Grande do Sul é dividido geograficamente em sete mesorregiões, as quais apresentam características distintas no processo social e econômico. Dentro deste contexto, o mapa 1 exibe a distribuição espacial das mesorregiões no estado, observa-se uma diferença no tamanho de cada mesorregião. A mesorregião Sudeste, a qual é objeto de estudo, é composta por 25 municípios $^{1}$ tem $15,76 \%$ da área do total do estado e possui uma posição estratégica privilegiada com acesso marítimo a outras regiões do Brasil e do mundo. Além disso, a mesorregião se

\footnotetext{
${ }^{1}$ Arroio do Padre, Arroio Grande, Caçapava do Sul, Candiota, Canguçu, Capão do Leão, Cerrito, Chuí, Cristal, Encruzilhada do Sul, Herval, Jaguarão, Morro Redondo, Pedras Altas, Pedro Osório, Pelotas, Pinheiro Machado, Piratini, Rio Grande, Santa Vitória do Palmar, Santana da Boa Vista, São José do Norte, São Lourenço do Sul e Turuçu.
} 
conecta por rodovia, hidrovia e ferrovia com outras mesorregióes do estado e outros estados do Brasil.

Figura 1 - Mapa de mesorregiões do Rio Grande do Sul

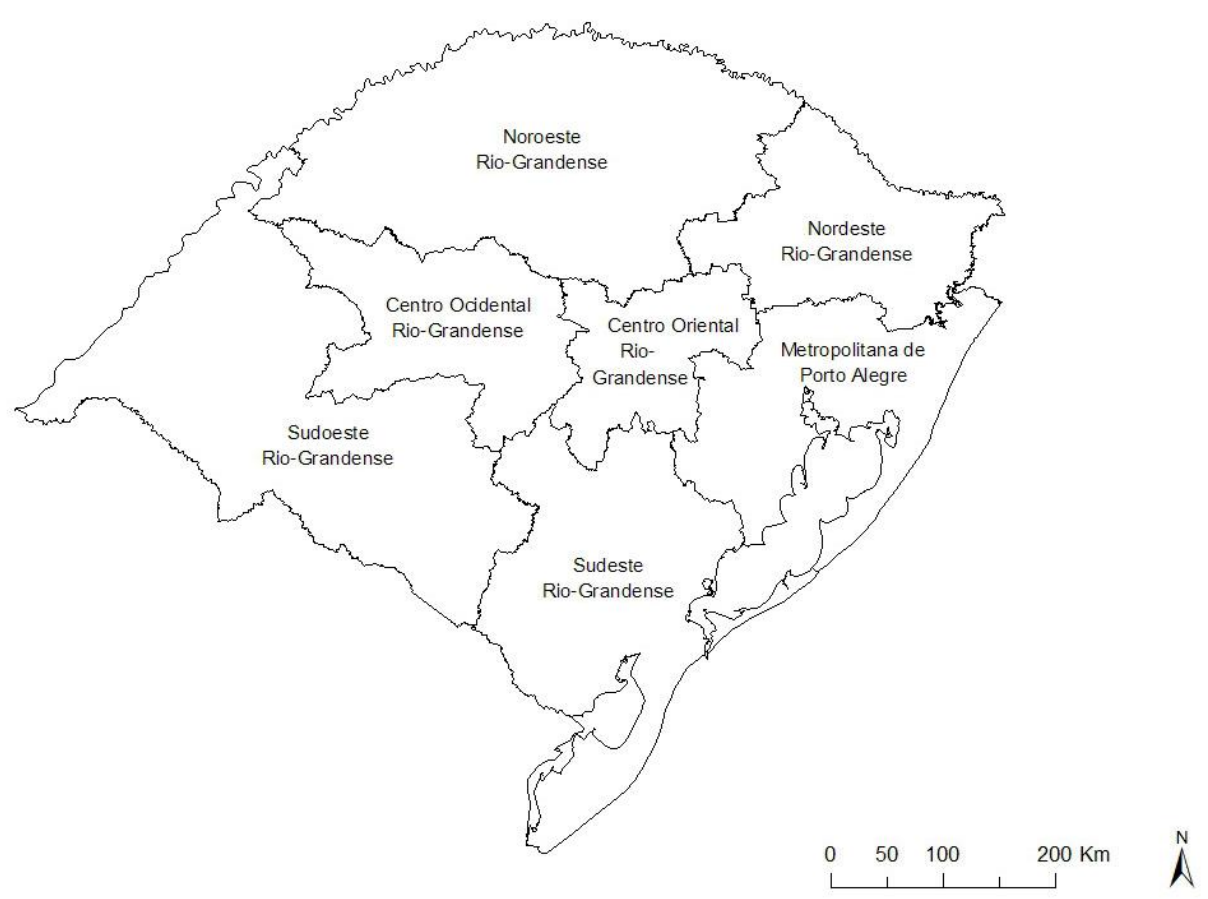

Fonte: Elaboração própria a partir da base de dados do IBGE.

A tabela 1 demonstra que existe uma diferença significativa no padrão de desenvolvimento econômico das mesorregiões do Rio Grande do Sul. A mesorregião Sudeste Rio-Grandense possui o quinto maior PIB e o quarto maior contingente populacional do estado. Apesar das potencialidades, a mesorregião possui os piores indicadores sociais de saúde e educação. Os dados da tabela 1 demonstram que a região enfrenta historicamente problemas estruturais que dificultam o desenvolvimento econômico.

Tabela 1 - Indicadores sociais e econômicos das mesorregiões do RS em 2013

\begin{tabular}{cccccccc}
\hline Mesorregiões & $\begin{array}{c}\text { Bloco } \\
\text { saúde }\end{array}$ & $\begin{array}{c}\text { Bloco } \\
\text { educação }\end{array}$ & $\begin{array}{c}\text { Bloco } \\
\text { Renda }\end{array}$ & $\begin{array}{c}\text { IDESE } \\
\text { PIB em RS } \\
\text { milhões }\end{array}$ & $\begin{array}{c}\text { População } \\
\text { capita em } \\
\text { R\$̦ }\end{array}$ \\
\hline $\begin{array}{c}\text { Ocidentro } \\
\text { Centro Oriental }\end{array}$ & 0.81 & 0.69 & 0.75 & 0.73 & $12.503,4$ & 551.614 & $22.666,91$ \\
Metropolitana & 0.80 & 0.71 & 0.74 & 0.76 & $24.657,9$ & 811.698 & $30.378,22$ \\
Nordeste & 0.86 & 0.71 & 0.83 & 0.80 & $43.563,9$ & 1.114 .481 & $39.088,92$ \\
Noroeste & 0.83 & 0.73 & 0.76 & 0.77 & $61.005,1$ & 2.008 .595 & $30.372,04$ \\
Sudeste & 0.76 & 0.63 & 0.70 & 0.68 & $20.418,1$ & 943.767 & $21.634,66$ \\
Sudoeste & 0.77 & 0.67 & 0.66 & 0.69 & $14.118,3$ & 736.667 & $19.165,07$ \\
\hline
\end{tabular}

Fonte: Elaboração própria a partir de dados da FEE.

Observação: IDESE é o Índice de Desenvolvimento Socioeconômico elaborado pela FEE para o RS. 
Na tabela 2, apresentamos a taxa de crescimento do registro de veículos nas mesorregiões no RS, percebemos que o número de veículos registrados no estado aumentou consideravelmente, principalmente entre 2016 e 2001. Na mesorregião Sudeste, o incremento maior ocorreu no segmento de passageiros com crescimento de 224\% passando de 192269 em 2001 para 431828 em 2016 e nos veículos de carga a taxa de crescimento foi de $178 \%$ passando de 34585 para 61756.

De acordo com os dados da Confederação Nacional de Transporte (CNT), em 2014, aproximadamente $85 \%$ do transporte de cargas e $90 \%$ de passageiros no RS ocorre por via rodoviária. Além disso, o incremento considerável no número de veículos registrados na mesorregião Sudeste afeta diretamente a competividade do Porto de Rio Grande, pois exerce uma pressão na utilização da BR 116, aumentando o tempo de deslocamento e gerando sobrecarga na infraestrutura da rodovia.

Tabela 2 - Taxa de crescimento de registro de veículos de passageiros e carga no RS

\begin{tabular}{lllllll}
\hline Mesorregião & \multicolumn{3}{c}{ Passageiros } & \multicolumn{3}{c}{ Cargas } \\
\hline Período & $\mathbf{2 0 0 1 / 1 9 9 1}$ & $\mathbf{2 0 1 1} / \mathbf{2 0 0 1}$ & $\mathbf{2 0 1 6 / 2 0 0 1}$ & $\mathbf{2 0 0 1 / 1 9 9 1}$ & $\mathbf{2 0 1 1 / 2 0 0 1}$ & $\mathbf{2 0 1 6 / 2 0 0 1}$ \\
\hline Ocidental & $161,36 \%$ & $180,37 \%$ & $\mathbf{2 2 7 , 9 4 \%}$ & $191,08 \%$ & $140,35 \%$ & $185,93 \%$ \\
Oriental & $167,34 \%$ & $189,69 \%$ & $\mathbf{2 3 3 , 3 5 \%}$ & $\mathbf{1 8 2 , 3 5 \%}$ & $149,23 \%$ & $195,36 \%$ \\
Metropolitana & $\mathbf{1 6 4 , 4 7 \%}$ & $160,97 \%$ & $197,03 \%$ & $183,06 \%$ & $123,46 \%$ & $154,99 \%$ \\
Nordeste & $179,07 \%$ & $178,58 \%$ & $\mathbf{2 1 4 , 6 9 \%}$ & $194,15 \%$ & $128,84 \%$ & $159,65 \%$ \\
Noroeste & $159,38 \%$ & $186,94 \%$ & $236,74 \%$ & $179,92 \%$ & $136,08 \%$ & $185,40 \%$ \\
Sudeste & $163,97 \%$ & $172,41 \%$ & $\mathbf{2 2 4 , 6 0 \%}$ & $172,55 \%$ & $131,99 \%$ & $178,56 \%$ \\
Sudoeste & $148,76 \%$ & $156,74 \%$ & $\mathbf{2 0 4 , 4 7 \%}$ & $183,91 \%$ & $113,87 \%$ & $144,03 \%$ \\
\hline RS & $\mathbf{1 6 3 , 9 8 \%}$ & $\mathbf{1 7 0 , 6 9 \%}$ & $\mathbf{2 1 2 , 0 7 \%}$ & $\mathbf{1 8 3 , 4 6 \%}$ & $\mathbf{1 2 9 , 3 6 \%}$ & $\mathbf{1 6 7 , 1 2} \%$ \\
\hline
\end{tabular}

Fonte: Elaboração própria a partir de dados do IBGE.

Uma possibilidade de minimização desse problema logístico é o término de duplicação da BR $116^{2}$ e a maior utilização da BR 101 no trecho Sul (São José do Norte e Osório), o qual conecta a mesorregião a outras mesorregiões do Rio Grande do Sul e a outros estados. Porém, no caso da BR 101, a travessia pela lagoa dos patos entre São José do Norte e Rio Grande é realizada por lancha para o transporte de passageiros e por balsa para o transporte de cargas, isso diminui o interesse pelo uso da rodovia, em virtude do tempo da travessia.

\footnotetext{
${ }^{2}$ Segundo a CNT, a BR-116 é a principal rodovia federal do país, é uma rodovia longitudinal que tem início em Fortaleza/Ceará e término em Jaguarão/RS, totalizando em torno de $4500 \mathrm{~km}$ de extensão no território nacional. No estado do Rio Grande do Sul a rodovia possui uma extensão aproximada de $600 \mathrm{~km}$, com destaque para o trecho Pelotas/Guaíba em fase de duplicação, que liga o estado ao Porto de Rio Grande e a capital do estado.
} 
Figura 2 - Mapa do trecho sul da BR 116

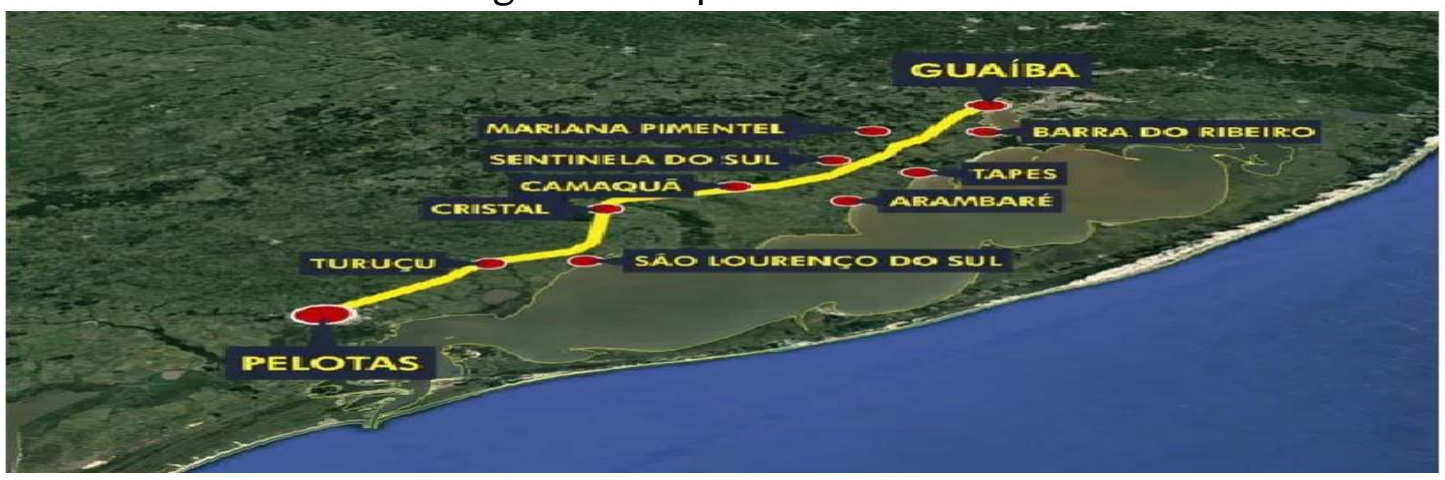

Fonte: Detran3/RS 2016.

A figura 2 demonstra o trecho sul da BR 116 (Pelotas-Guaíba). Percebe-se que a duplicação do trecho é fundamental para o aumento no fluxo rodoviário do estado, e para o desenvolvimento dos municípios localizados ao longo deste trecho, tais como, São Lourenço, Turuçu, Cerrito e Cristal em função na melhoria na acessibilidade.

Ademais, a Secretaria de Planejamento e Gestão (SEPLAG, RS) 2015 enfatiza que grande parte da produção do RS é escoada pelo Porto do Rio Grande, o que acarreta gargalos devido à grande parcela de produtos que utilizam transporte de cargas por modal rodoviário, com alto número de acidentes e congestionamentos. Por isso, o término da duplicação seria fundamental não somente para a mesorregião, mas também para todo o estado.

Dessa forma, a estimação da MIP da mesorregião Sudeste demonstra o perfil econômico e setorial da região, tendo como base os efeitos econômicos dos multiplicadores e a abertura dos setores de transporte. Ademais, permite vislumbrar a contribuição que cada tipo de transporte por mercadoria, fornecendo subsídios para formulação de políticas públicas para o setor e para a região em questão.

\section{Matriz insumo produto: definições teóricas e evidências empíricas}

A abordagem de matriz insumo produto (MIP) consiste num arcabouço analítico que mapeia as relações intersetoriais dos agentes que compõe o sistema econômico, sendo considerada uma ferramenta de planejamento econômico, disponível ao formulador de política pública. A partir desse instrumental, pode-se avaliar o impacto de políticas setoriais e seus efeitos sobre uma economia nacional e/ou regional.

Os trabalhos iniciais de MIP são fundamentados e inspirados nas contribuições de Quesnay sobre o fluxo circular de renda e no modelo de equilíbrio geral simplificado proposto por Walras. O economista e matemático Wasily Leontief foi o pioneiro com a formulação do modelo de insumo produto em seu artigo

3 http://www.detran.rs.gov.br/conteudo/44747/trecho-nao-duplicado-da-br-116-registrou-38-mortesem-2016

4 Para maiores detalhes: http://planejamento.rs.gov.br/upload/arquivos/201603/17095141-perfisregionais-2015-sul.pdf 
seminal em 1936, construindo um instrumental que possibilitou uma análise sobre as relações intersetoriais na produção.

O modelo básico (produção) de Leontief é geralmente construído a partir de dados para uma região geográfica específica (nação, regional, mesorregião e etc.). A informação fundamental utilizada na análise diz respeito aos fluxos de produtos de cada setor econômico, considerado produtor e/ou consumidor cada um dos setores, dada as interações setoriais. Conforme Miller e Blair (2009) as linhas descrevem a distribuição da produção de um produtor em toda a economia (vendas) e as colunas a composição dos insumos exigidos por um determinado setor produzir um produto (compras).

O modelo de produção possibilita a comparação entre os impactos que a adoção de determinadas políticas tem sobre uma nação e/ou uma região e quais as repercussões intersetoriais, partindo da pressuposição que ocorreram modificações na demanda final. Dessa forma, dado o encadeamento dos setores da economia em análise, pode-se verificar quais setores são impactados, quais as magnitudes e os setores mais sensíveis a modificações na demanda final.

Conforme Miller e Blair (2009) B é a matriz dos coeficientes técnicos diretos e indiretos, mais conhecida como matriz inversa de Leontief.

$$
B=(I-A)^{-1}
$$

A matriz A representa a matriz dos coeficientes técnicos diretos, ou seja, a matriz que fornece o impacto direto causado pelo aumento na demanda final, enquanto que ( $1-A)-1$, além dos efeitos diretos, avalia também os indiretos. Portanto, o modelo definido na equação (1) é o que permitirá avaliar o impacto total que uma variação na demanda final causará na produção da economia, dado o aumento da demanda em uma unidade.

Partindo dos multiplicadores da matriz B de Leontief, diversas análises são realizadas, com relação a variáveis como emprego, renda, produto e etc. Além disso, a partir da matriz $\mathbf{B}$ também se pode encontrar os índices de ligação e setores econômicos chave ${ }^{5}$. A evolução das técnicas de I-P tem permitido a análise de modelos regionais e interregionais, sendo necessária para isso a estimação de matrizes insumo produto. A seguir, apresenta-se um resumo da literatura econômica sobre a regionalização de MIPs.

Originalmente, as aplicações do modelo insumo produto foram realizadas a nível nacional, porém modificações teóricas conduziram a modificações no modelo original, permitindo assim análises de questões regionais (MILLER; BLAIR, 2009).

A estrutura de produção de uma determinada região pode ser idêntica ou diferir significativamente de uma matriz nacional, por isso, para aplicações regionais precisa-se levar em consideração a relação entre os coeficientes técnicos da tabela nacional e da matriz regional a ser estimada. Além disso, quanto menor for a região analisada, mais dependente será essa economia com relação ao comércio externo (MILLER; BLAIR, 2009).

Ademais, as matrizes regionais e/ou interregionais possuem as mesmas identidades contábeis de uma matriz nacional, existindo sempre um equilíbrio entre oferta e demanda agregada, porém questões relacionadas ao comércio exterior e

${ }^{5}$ Miller e Blair (2009) apresentam formalmente diversos métodos de análise. 
ao nível de governo são diferentes. Com isso, surgem vetores de importações e exportações regionais e/ou interregionais. Wiebusch (2007) menciona que trabalhos com matrizes insumo-produto regionais precisam levar em conta dados regionais, mesmo que os coeficientes técnicos adotados sejam os mesmos a nível nacional.

Nesse sentido, Guilhoto (2011) diz que uma matriz regional apresenta a mesma estrutura de uma matriz nacional, tendo como diferença básica a discriminação da exportação (importação) para as outras regiões do país e a exportação (importação) para outros países. Por sua vez, a matriz de modelos interregionais, os quais são inspirados no modelo Isard (1951), requerem uma grande massa de dados reais ou estimados, principalmente quanto às informações sobre fluxos intersetoriais e interregionais.

Ribeiro (2013) salienta que para a estimação das matrizes regionais, a literatura internacional indica dois métodos: os censitários e os não censitários. Sendo o segundo recomendado quando sem tem carência de estatísticas regionais, à medida que os métodos censitários possuem uma aplicação complexa e necessitam de uma grande quantidade de informações. O método não censitário mais conhecido é o RAS e pode ser visto em Stone (1966) e Bacharach (1970) para estimação de matrizes regionais.

A literatura apresenta ainda técnicas de estimação de matrizes que utilizam características de economias regionais por meio de um processo de ajustamento da matriz nacional de coeficientes técnicos, utilizando estimativas de porcentagens de oferta para cada setor da região estudada, trabalhos como Isard e Kuenne (1953) e Miller (1957).

Por outro lado, Ribeiro (2013) salienta que, no Brasil, destacam-se duas técnicas de regionalização de matrizes de coeficientes técnicos: i) O método do quociente locacional $^{6}(\mathrm{QL})$ e ii) $\mathrm{O}$ método de biproporcionalidade RAS. O primeiro método considera o ajuste dos coeficientes técnicos a partir da relação entre duas economias a regional e a nacional, geralmente, leva em consideração se um determinado setor tem, comparativamente, uma concentração maior na região ou fora dela, principalmente, através do número de empregos. Já o segundo utiliza as proporções de uma matriz nacional, partindo de estatísticas regionais, faz o ajustamento de linhas e colunas, visando garantir o equilíbrio das identidades de contabilidade social.

No Brasil, a literatura de estudos com matrizes insumo produto é extensa, tanto com a estimação de modelos interregionais como regionais. Por isso, a seguir realiza-se uma revisão dos principais trabalhos empíricos, no país, com modelos regionais, buscando conhecer com maior riqueza de detalhes os métodos de regionalização de matrizes. Além disso, pode-se ver modelos interregionais em Haddad e Domingues (2003); Figueiredo et al. (2005); Perobelli et al. (2007).

\footnotetext{
${ }^{6} \mathrm{O}$ principal problema do quociente locacional é que considera a hipótese de que as tecnologias setoriais regionais e nacionais são as idênticas.
} 
Quadro 1 - Síntese da literatura nacional sobre Matriz Insumo Produto Regional

\begin{tabular}{|c|c|c|c|c|}
\hline Autores & $\begin{array}{ll}\text { Estado } & \text { ou } \\
\text { região }\end{array}$ & Objetivo & $\begin{array}{l}\text { Método de } \\
\text { regionalização }\end{array}$ & Principais resultados \\
\hline $\begin{array}{l}\text { Brene } \\
\text { et al. } \\
\text { (2011) }\end{array}$ & $\begin{array}{l}\text { Município de } \\
\text { São Bento do } \\
\text { Sul }\end{array}$ & $\begin{array}{l}\text { Estimaram a matriz de insumo } \\
\text { produto municipal de São } \\
\text { Bento do Sul (Santa Catarina), } \\
\text { a partir da matriz do Brasil } \\
\text { estimada para } 2007 \text { por meio } \\
\text { da metodologia Guilhoto e } \\
\text { Sesso Filho (2005) e, } \\
\text { utilizando dados municipais do } \\
\text { mesmo ano, buscando calcular } \\
\text { os indicadores econômicos } \\
\text { para identificar setores-chave } \\
\text { para o desenvolvimento } \\
\text { econômico e social do } \\
\text { município. }\end{array}$ & $\begin{array}{ll}\text { Método do } \\
\text { Quociente } \\
\text { Locacional }\end{array}$ & $\begin{array}{l}\text { Os resultados demonstram que } \\
\text { o setor de madeira e móveis foi } \\
\text { importante na produção e } \\
\text { emprego, porém, não aparece } \\
\text { como maior multiplicador de } \\
\text { produto e renda, com destaque } \\
\text { para os setores de siderurgia, } \\
\text { comércio, serviços prestados à } \\
\text { família e administração pública. }\end{array}$ \\
\hline $\begin{array}{l}\text { Ribeiro } \\
\text { e Santos } \\
(2012)\end{array}$ & $\begin{array}{ll}\text { Estado de } \\
\text { Sergipe }\end{array}$ & $\begin{array}{l}\text { Quantificaram a estrutura } \\
\text { produtiva do Estado de } \\
\text { Sergipe por meio da } \\
\text { estimação de uma matriz } \\
\text { insumo produto, visando } \\
\text { oferecerem indicações } \\
\text { analíticas obtidas com os } \\
\text { indicadores estruturais de } \\
\text { oferta de insumos, produtos, } \\
\text { emprego e renda, servindo de } \\
\text { subsídios para as políticas de } \\
\text { planejamento do Estado. }\end{array}$ & Método RAS & $\begin{array}{l}\text { Os resultados demonstram que } \\
\text { Químicos e petroquímicos, } \\
\text { Agricultura, silvicultura, } \\
\text { exploração florestal, Têxteis, } \\
\text { SIUP possuem os maiores } \\
\text { multiplicadores. Por outro lado, } \\
\text { as atividades econômicas } \\
\text { Alimentos e bebidas, Têxteis, } \\
\text { Papel e celulose, Borracha e } \\
\text { plástico foram classificadas } \\
\text { como setores-chave da } \\
\text { economia sergipana em 20o6. } \\
\text { Segundo os autores, a } \\
\text { economia sergipana apresenta } \\
\text { sérios problemas na estrutura } \\
\text { de oferta de insumos em } \\
\text { setores crucias para o } \\
\text { desenvolvimento do estado, } \\
\text { além de concentrada } \\
\text { setorialmente e baixa inserção } \\
\text { internacional. }\end{array}$ \\
\hline $\begin{array}{l}\text { Ribeiro } \\
\text { et al. } \\
(2013)\end{array}$ & $\begin{array}{l}\text { Estado de } \\
\text { Minas Gerais }\end{array}$ & $\begin{array}{l}\text { Formularam uma matriz de } \\
\text { insumo-produto (MIP) de } \\
\text { Minas Gerais, ano base 2009, } \\
\text { buscando auxiliar no } \\
\text { planejamento de políticas } \\
\text { públicas e contribuir para o } \\
\text { fortalecimento dos setores } \\
\text { produtivos em Minas Gerais. }\end{array}$ & Método RAS & $\begin{array}{l}\text { Os resultados indicaram alguns } \\
\text { setores importantes para o } \\
\text { dinamismo da economia } \\
\text { mineira, tais como, alimentos e } \\
\text { bebidas, têxteis, produtos } \\
\text { químicos diversos, artigos de } \\
\text { borracha e plástico, e siderurgia } \\
\text { e metalurgia. Considerando tais } \\
\text { setores relacionados às } \\
\text { indústrias tradicionalmente } \\
\text { relevantes na economia } \\
\text { mineira, torna-se importante } \\
\text { investimentos em infraestrutura } \\
\text { e uma carga tributária menor e } \\
\text { disponibilização de crédito as } \\
\text { referidas indústrias. }\end{array}$ \\
\hline $\begin{array}{l}\text { Nunes e } \\
\text { Melo } \\
(2012)\end{array}$ & $\begin{array}{l}\text { Mesorregião } \\
\text { Sudeste } \\
\text { Paranaense }\end{array}$ & $\begin{array}{l}\text { Elaboram uma matriz de } \\
\text { insumo produto da região } \\
\text { Sudeste Paranaense para o } \\
\text { ano de 2009, buscando } \\
\text { identificar os setores-chave, } \\
\text { bem como os efeitos de }\end{array}$ & $\begin{array}{ll}\text { Método do } \\
\text { Quociente }\end{array}$ & $\begin{array}{l}\text { Os resultados evidenciaram que } \\
\text { algumas atividades não } \\
\text { tradicionais possuem altos } \\
\text { índices de desempenho } \\
\text { econômico, os índices de } \\
\text { ligação normalizados de }\end{array}$ \\
\hline
\end{tabular}




\begin{tabular}{|c|c|c|c|c|}
\hline & & $\begin{array}{l}\text { ligação e multiplicadores de } \\
\text { produção, emprego e renda. }\end{array}$ & & $\begin{array}{l}\text { Rasmussen-Hirschmann } \\
\text { permitiram verificar que oito } \\
\text { setores apresentaram índices } \\
\text { de ligação para frente maior } \\
\text { que um, e doze setores tiveram } \\
\text { índices de ligação para trás } \\
\text { superiores à unidade e dois } \\
\text { setores foram considerados } \\
\text { chaves (indústria química e } \\
\text { metalurgia). Com relação aos } \\
\text { multiplicadores destacaram-se, } \\
\text { material elétrico e eletrônico } \\
\text { (produção), alimentos e } \\
\text { bebidas (renda) e material de } \\
\text { transporte (emprego). }\end{array}$ \\
\hline $\begin{array}{l}\text { Leivas e } \\
\text { Feijó } \\
(2014)\end{array}$ & $\begin{array}{l}\text { COREDE SUL } \\
\text { (RS) }\end{array}$ & $\begin{array}{l}\text { Estimaram a Matriz Insumo } \\
\text { Produto do Conselho Regional } \\
\text { de Desenvolvimento da } \\
\text { Região Sul do Estado do Rio } \\
\text { Grande do Sul, buscando } \\
\text { identificar os segmentos- } \\
\text { chave para a economia da } \\
\text { Região e calculando } \\
\text { multiplicadores de impacto } \\
\text { intersetorial para a produção, } \\
\text { Valor Adicionado e emprego. }\end{array}$ & $\begin{array}{ll}\text { Método do } & \text { duociente } \\
\text { Locacional } & \end{array}$ & $\begin{array}{l}\text { Segundo os autores os } \\
\text { resultados mostraram que a } \\
\text { Região apresenta uma } \\
\text { economia pouco diversificada e } \\
\text { não muito dinâmica, com } \\
\text { segmentos-chave relacionados, } \\
\text { basicamente, aos setores } \\
\text { agroindustriais e de serviços. } \\
\text { Quanto aos setores-chave, a } \\
\text { Região apresentou seis } \\
\text { atividades que podem ser } \\
\text { consideradas fundamentais, na } \\
\text { perspectiva do encadeamento } \\
\text { para a frente, isto é, na venda } \\
\text { de insumos, quais sejam: } \\
\text { agropecuária, silvicultura, } \\
\text { exploração vegetal e pesca; } \\
\text { refino do petróleo; comércio; } \\
\text { transporte; serviços prestados } \\
\text { às famílias e às empresas; e } \\
\text { indústria química. Por outro } \\
\text { lado, os setores-chave com } \\
\text { encadeamento para trás, foram: } \\
\text { fabricação de óleos vegetais; } \\
\text { indústria de laticínios; } \\
\text { beneficiamento de produtos } \\
\text { vegetais; abate de animais; } \\
\text { outros produtos alimentares; } \\
\text { transporte; refino do petróleo; } \\
\text { indústria química; indústrias } \\
\text { diversas; e comércio. }\end{array}$ \\
\hline
\end{tabular}

Fonte: Elaboração própria.

Com relação a aplicações de modelos regionais de insumo produto no Rio Grande do Sul, destacam-se os trabalhos de Porsse et al. (2004) e Porsse et al. (2008), os quais estimam matrizes inter-regionais Rio Grande do Sul e o Restante do Brasil a partir de Técnicas RAS. Por outro lado, Wiebusch (2007) e Leivas e Feijó (2014) estimaram matrizes insumo produto para os COREDEs Vale do Taquari e Sul a partir da regionalização do consumo intermediário pelo Quociente Locacional.

Percebe-se que os métodos RAS e o Quociente Locacional são as principais técnicas utilizadas na regionalização de matrizes insumo produto no Brasil. Observase ainda uma carência de trabalhos que estimam MIPs por mesorregião de um estado. No caso específico do Rio Grande do Sul e da mesorregião Sudeste, a 
literatura empírica indica que não existe nenhum trabalho que estime matrizes por mesorregião no estado, isso ressalta a relevância deste trabalho, principalmente com a estimação das exportações e importações para outras mesorregiões e a decomposição de margens por tipo de transporte.

Dessa forma, o cálculo de multiplicadores de produto, emprego e renda, impostos e etc. proporciona um conhecimento da estrutura setorial da economia em questão. Sendo o multiplicador de produto $M P_{j}$ a principal referência do nível de atividade econômica, obtido pela soma das colunas de $b_{i j}$, demostra quanto determinado setor coluna $(j)$ pode gerar de produção em todos os setores da economia, de acordo com a alteração de uma unidade monetária da demanda final total, em relação à produção do setor j. Formalmente:

$$
M P=\sum_{1=i}^{n} b_{i j}
$$

Tendo $b_{i j}$ como um elemento pertencentes a matriz inversa de Leontief $B$.

Além disso, quando se relaciona a variável de interesse com a produção obtémse o coeficiente direto da variável em questão:

$$
v_{j}=\frac{V_{j}}{X_{j}}
$$

A partir dos coeficientes diretos apresentando na equação (3), chega-se ao impacto total, direto, e indireto sobre a variável de interesse, definido como geradores:

$$
G V_{j}=\sum_{1=i}^{n} b_{i j} v_{i}
$$

Sendo variável de interesse valor adicionado, pode-se encontrar o multiplicador por meio da seguinte equação:

$$
V A_{j}=\sum_{1=i}^{n} b_{i j} v a_{i}
$$

Onde $v a_{i}$ é a razão entre o Valor Adicionado Bruto e o Valor Bruto da Produção, demonstra a variação ocorrida no Valor Adicionado Bruto do setor $j$ devido a uma variação unitária na demanda final.

A partir desse instrumental, é possível construir um simulador que mensura como os choques de demanda afetam a demanda intermediária por setor. Tal simulador pode ser descrito matematicamente da seguinte forma: 


$$
S P_{j}=\sum_{1=i}^{n} b_{i j} \cdot \text { choque }
$$

Onde $S P_{j}$ representa qual o impacto em cada setor de um determinado choque de demanda, principalmente como o setor que recebe o choque reage direta e indiretamente.

Além disso, pode-se mensurar o impacto de choques em determinadas variáveis em valores monetários, partindo dos multiplicadores de produção, valor adicionado e emprego. No caso deste trabalho, mensuram-se como os choques negativos de margens de transportes afetam a economia em valores monetários por meio dos multiplicadores. Os impactos setoriais da redução das margens podem ser visualizados:

$$
I M V_{j}=\sum_{1=j}^{n} M V_{j} . \text { choquen }
$$

Onde: $I M V_{j}$ representa qual o impacto em monetário setorial de determinado choque de margens de transporte choquem(margens de transportes em valores monetários após o choque), partindo do respectivo multiplicador $M V_{j}$ que pode ser produção, valor adicionado e/ou emprego.

Neste trabalho, os multiplicadores limitam-se ao consumo intermediário, ou seja, são analisados apenas os indicadores denominados por Guilhoto (2011) do tipo 1. Visto que, a partir da estimação das matrizes insumo produto de cada região do Rio Grande do Sul, busca-se entender as diferenças setoriais do nível de atividade econômica e de desenvolvimento econômico.

Quando o objetivo é verificar como os setores estão interligados nas compras e nas vendas com outros setores, utilizam-se os índices de ligação para trás e para frente. Tais indicadores foram formulados por Rasmussen (1956) e Hirschman (1958), mensuram o poder de dispersão dos encadeamentos a montante, ou para trás, e o índice de sensibilidade de dispersão dos encadeamentos a jusante, ou para frente.

Desse modo, considerando (B) como a matriz inversa de Leontief, $b_{i j}$ como sendo um elemento da matriz inversa de Leontief, $B^{*}$ como sendo a média de todos os elementos de (B), $b_{j}$ e $b_{i}$ como sendo respectivamente a soma de uma coluna e de uma linha típica de (B), tem-se formalmente os índices de ligação para trás e para frente, como apresentado nas equações 8 e 9.

Índices de ligações para trás (poder da dispersão):

$$
U_{j}=\left[B_{j} / n\right] / B^{*}
$$

Índices de ligações para frente (sensibilidade da dispersão):

$$
U_{i}=\left[B_{i} / n\right] / B^{*}
$$


Onde $U_{j}$ é o coeficiente de ligação para trás, o qual mostra quanto é demandado por cada setor em seus encadeamentos para trás, ou seja, quanto um determinado setor compra dos outros setores. Por outro lado, $U_{i}$ é o coeficiente de ligação para frente, o qual demonstra o quanto é ofertado por cada setor em seus encadeamentos para frente, ou seja, quanto um determinado setor vende para os outros setores da economia.

Conforme Miller e Blair (2009), a partir dos resultados dos índices anteriores, surgem quatro classificações dependendo dos resultados: i) independentes ou pouco relacionados, quando ambos os índices forem inferior a 1; ii) dependentes ou fortemente relacionados, quando os dois índices simultaneamente forem superior a 1; iii) dependentes da oferta interindustrial, quando somente o índice de ligação para trás for maior do que 1; e iv) dependentes da demanda interindustrial, quando somente o índice de ligação para frente for superior a 1.

Segundo a literatura de MIP, os índices anteriores podem apresentar deficiências, por isso, existem outros coeficientes para minimizar tais problemas ${ }^{7}$. Porém, os índices de ligação para trás e para frente são suficientes para indicar a estrutura setorial da mesorregião, principalmente dos setores de transporte.

\subsection{Procedimentos para estimação da matriz da mesorregião Sudeste do RS}

A estimação da MIP interregional para a mesorregião Sudeste do Rio Grande do Sul para o ano de 2011 começa com a coleta de informações sobre o Estado oriundas das contas regionais do IBGE para 2011. Além disso, utilizou-se como base os dados da MIP 2010 nacional, sobretudo a estrutura setorial e produtiva.

Ainda que a última MIP divulgada de 2010 apresente um detalhamento de produtos e setores, torna-se necessário a compatibilização das contas regionais do IBGE com a Relação Anual de Informações (RAIS) de 2011 sobre o mercado de trabalho da mesorregião e posteriormente a padronização das contas regionais com a última MIP estadual (a qual segue estrutura semelhante a matriz nacional). A compatibilização da RAIS foi realizada pela Classificação Nacional de Atividades Econômicas $(\mathrm{CNAE})^{8}$ 2.0, seguindo expressamente a comissão de classificação do IBGE as 672 atividades foram classificadas em 70 setores, conforme demonstra a tabela abaixo.

\footnotetext{
7 Guilhoto (2011) menciona que os índices puros de ligação e a análise do campo de influência corrigem possíveis distorções dos índices de ligação para trás e para frente.

${ }^{8}$ https://concla.ibge.gov.br/documentacao/documentacao-cnae-2-o.html
} 
Tabela 3 - Estrutura setorial da MIP da mesorregião Sudeste do RS

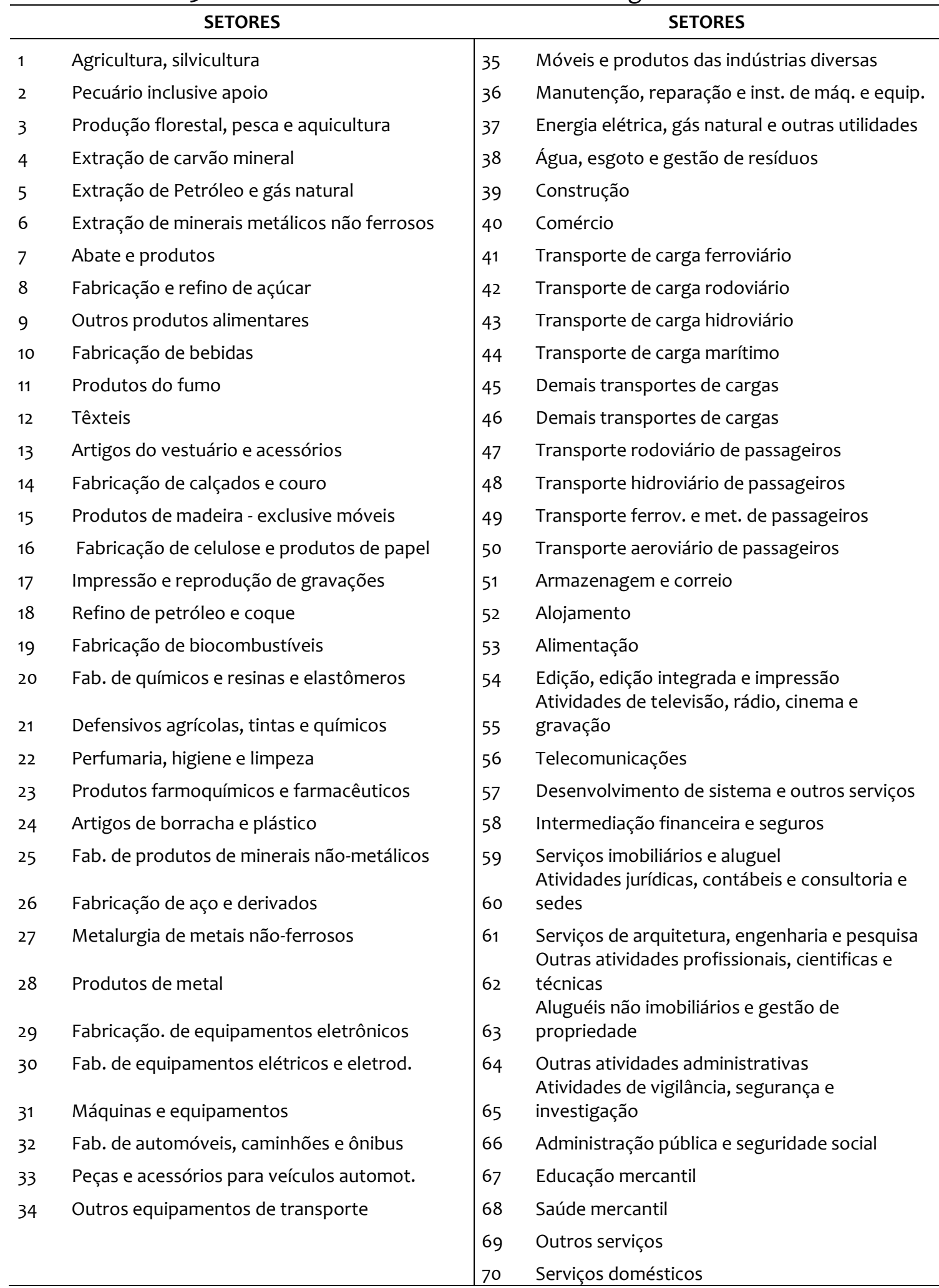

Fonte: Elaboração própria.

A partir da estimação de uma matriz estadual para o ano de 2011, elaborada com dados das contas regionais do IBGE e equilibrada a partir do método RAS, foi regionalizada pelo método do Quociente Locacional $(\mathrm{QL})$ uma matriz para a mesorregião Sudeste. Primeiramente, calculamos o QL com dados de emprego para 
o RS e da mesorregião e os respectivos coeficientes técnicos e, posteriormente, encontramos os vetores de consumo intermediário, valor adicionado bruto, valor bruto da produção da mesorregião e a decomposição da demanda final.

Nesse trabalho, os valores das margens de comércio e de transportes, bem como os outros impostos foram distribuídos ao longo de todos os vetores para o RS como um todo. Posteriormente, as margens e os impostos foram regionalizados para a mesorregião, seguindo a estrutura de produção para as margens de comércio e impostos.

Porém, no tocante às margens de transporte, o procedimento foi diferente, uma vez que a abertura dos setores de transporte permitiu a possibilidade da decomposição das margens de transporte de cargas. As margens para o transporte de cargas foram desagregadas em cincos modalidades: 1) transporte de carga rodoviário, 2) transporte de carga ferroviário, 3) transporte de carga hidroviário, 4) transporte de carga hidroviário e 5) demais transportes de cargas. Cabe salientar que a distribuição do tipo de transporte por setor e produto foi realizada com base na matriz de 2010. Além disso, a definição do tipo de transporte de carga, seguiu a denominação da CNAE 2.o por classe na RAIS 2011.

Por sua vez, com relação a regionalização das modalidades para a mesorregião, o procedimento adotado foi a participação da mesorregião na utilização dos diferentes modais, isso foi realizado com base nas estatísticas de transporte da Confederação Nacional de Transporte (CNT), Agência Nacional dos Transportes Ferroviários (ANTAF) e Agência Nacional dos Transportes Aquaviários (ANTAQ) e na distribuição setorial do emprego pela RAIS em (2011).

A estimação das margens de comércio e transporte entre as mesorregiões partiu dos dados de gravitação, levando em conta os fluxos de comércio interregionais. Dessa forma, foi possível encontrar os valores das margens interregionais, ou seja, quanto a mesorregião paga as demais mesorregiões de transporte e comércio.

Cabe mencionar que as margens de transporte para a mesorregião podem ser desagregadas em um sistema interregional em: i) margem para o resto do mundo; ii) margem para o resto do Brasil; iii) margem para as outras mesorregiões e iv) margem para a mesorregião.

\section{Resultados e discussões}

A MIP proporciona uma descrição da estrutura produtiva de um país ou região, pois as informações obtidas pelos indicadores de análise da matriz viabilizam o planejamento de políticas públicas setoriais. Em função disso, torna-se relevante conhecer a estrutura econômica da mesorregião Sudeste.

Conforme demonstra a tabela 4, os setores com maior efeito na produção são respectivamente: abate e produtos; outros produtos alimentares; alimentação; pecuária inclusive apoio; perfumaria, higiene e limpeza; produtos de madeira; outros equipamentos de transporte; atividades de televisão, rádio, cinema, gravação de som e imagem; fabricação de aço e derivados; outros serviços; defensivos agrícolas, tintas e químicos diversos

No tocante aos resultados dos multiplicadores da produção para os setores de transporte, destacam-se os transportes de carga hidroviário, ferroviário e 
rodoviário com os maiores multiplicadores de produção para cargas. No segmento de passageiros, os transportes rodoviário e hidroviário, respectivamente, obtiveram maiores efeitos multiplicadores de produção.

Percebe-se que o perfil produtivo da mesorregião está relacionado as cadeias produtivas da pecuária e alimentos (abate e transformação), produção de florestas (plantação de pinus, produtos de madeira e resina) e a indústria da construção naval (outros equipamentos de transporte e fabricação de aço e derivados).

Tabela 4 - Multiplicador de produção da mesorregião Sudeste: Setores selecionados

\begin{tabular}{lc|c}
\hline Setores & MPROD & Ranking \\
\hline Abate e produtos & 2,4939 & 1 \\
Outros produtos alimentares & 2,0343 & 2 \\
Alimentação & 1,9506 & 3 \\
Pecuária inclusive apoio & 1,8483 & 4 \\
Perfumaria, higiene e limpeza & 1,8092 & 5 \\
Produtos de madeira - exclusive móveis & 1,7767 & 6 \\
Outros equipamentos de transporte & 1,7634 & 7 \\
Atividades de televisão, rádio, cinema, gravação de som e imagem & 1,7506 & 8 \\
Fabricação de aço e derivados & 1,6996 & 9 \\
Outros serviços & 1,6640 & 10 \\
Defensivos agrícolas, tintas e químicos diversos & 1,6345 & 12 \\
Transporte hidroviário de passageiros & 1,5994 & 13 \\
Construção & 1,5773 & 14 \\
Fabricação de químicos e resinas e elastômeros & 1,5717 & 15 \\
Transporte de carga hidroviário & 1,5553 & 18 \\
Transporte de carga ferroviário & 1,4798 & 25 \\
Transporte rodoviário de passageiros & 1,4434 & 29 \\
Demais transportes de carga & 1,4292 & 32 \\
Serviços imobiliários e aluguel & 1,0554 & 65 \\
Refino de petróleo e coque & 1,0274 & 66 \\
\hline
\end{tabular}

Fonte: Elaboração própria, resultados da pesquisa.

Com relação ao multiplicador de Valor Adicionado, o qual considera salários, lucros e impostos, os setores que possuem maior efeito multiplicador, na geração de valor, como evidencia a tabela 5 são respectivamente: comércio; transporte de carga rodoviário; agricultura, silvicultura; demais transporte de passageiros; construção; intermediação financeira e seguros; educação mercantil; armazenagem e correio; serviços imobiliários e aluguel e produção florestal; pesca e aquicultura No sentido oposto, refino de petróleo e coque e transporte de carga ferroviário são os setores que destacam-se por possuir baixa contribuição para geração de valor adicionado.

Concentrando-se nos resultados dos multiplicadores de Valor Adicionado para os setores de transporte, os que adicionam mais valor na mesorregião são: rodoviário de carga; demais transporte de passageiros; demais transporte de cargas 
e transporte rodoviário de passageiros. No caso do transporte rodoviário de carga, os resultados não surpreendem, uma vez que $85 \%$ de todas as cargas do RS passam pelas rodovias.

Cabe mencionar que a mesorregião Sudeste possui grande dependência na geração de valor adicionado as atividades ligadas aos segmentos comércio, construção, agropecuária e atividades de transporte e armazenagem em virtude do complexo portuário.

Tabela 5 - Multiplicador de Valor Adicionado da mesorregião Sudeste: Setores selecionados

\begin{tabular}{lc|c}
\hline Setores & MVAB & Ranking \\
\hline Comércio & 2,5437 & 1 \\
Transporte de carga rodoviário & 1,2244 & 2 \\
Agricultura, silvicultura & 1,2094 & 3 \\
Demais transporte de passageiros & 1,2024 & 4 \\
Construção & 1,1778 & 5 \\
Intermediação financeira e seguros & 1,1656 & 6 \\
Educação mercantil & 1,1278 & 7 \\
Armazenagem e correio & 1,1090 & 8 \\
Serviços imobiliários e aluguel & 1,1082 & 9 \\
Produção florestal, pesca e aquicultura & 1,0655 & 10 \\
Energia elétrica, gás natural e outras utilidades & 1,0164 & 11 \\
Serviços domésticos & 1,0000 & 12 \\
Outros produtos alimentares & 0,9993 & 13 \\
Outros serviços & 0,9598 & 14 \\
Água, esgoto e gestão de resíduos & 0,9552 & 15 \\
Demais transportes de carga & 0,5972 & 37 \\
Transporte rodoviário de passageiros & 0,5826 & 41 \\
Transporte de carga hidroviário & 0,4458 & 49 \\
Refino de petróleo e coque & 0,0896 & 63 \\
Transporte de carga ferroviário & 0,0008 & 64 \\
\hline Fonte: & &
\end{tabular}

Fonte: Elaboração própria, resultados da pesquisa.

Já com relação aos multiplicadores de emprego, por meio da tabela 6, podemos observar que os setores com maior efeito multiplicador de emprego são: comércio; outras atividades profissionais; produtos de madeira - exclusive móveis; transporte de carga rodoviário; demais transporte de passageiros; atividades de vigilância, segurança e investigação; educação mercantil; armazenagem e correio; produtos de madeira - exclusive móveis; alojamento e outros produtos alimentares. Além do transporte rodoviário de carga, destacam-se os transportes rodoviário de passageiros e hidroviário de cargas.

Os multiplicadores de emprego da mesorregião indicam que comércio, atividades técnicas e de educação, atividades logísticas e segurança possuem grande efeito multiplicador de emprego na região, por isso, a formulação de políticas voltadas para esses segmentos possui grande impacto no nível geral de emprego da região. 
Efeitos Econômicos da Duplicação da BR 116: uma análise para a Mesorregião Sudeste do Rio Grande do Sul 
Tabela 6 - Multiplicador de emprego da mesorregião Sudeste: Setores selecionados

\begin{tabular}{l|c|c}
\hline Setores & MEMP & Ranking \\
\hline Comércio & 30,3047 & 1 \\
Outras atividades profissionais, cientificas e técnicas & 20,6370 & 2 \\
Transporte de carga rodoviário & 20,1150 & 3 \\
Demais transporte de passageiros & 19,4341 & 4 \\
Atividades de vigilância, segurança e investigação & 17,5491 & 5 \\
Educação mercantil & 16,7094 & 6 \\
Armazenagem e correio & 15,9492 & 7 \\
Produtos de madeira - exclusive móveis & 15,2929 & 8 \\
Alojamento & 14,2001 & 9 \\
Outros produtos alimentares & 13,0503 & 10 \\
Abate e produtos & 11,9518 & 11 \\
Agricultura, silvicultura & 11,9202 & 12 \\
Outros serviços & 11,8022 & 13 \\
Móveis e produtos das indústrias diversas & 10,7948 & 14 \\
Construção & 10,7502 & 15 \\
Transporte rodoviário de passageiros & 3,8665 & 45 \\
Transporte de carga hidroviário & 1,9638 & 56 \\
Demais transportes de carga & 0,2050 & 61 \\
Transporte de carga ferroviário & 0,0089 & 63 \\
Extração de minerais metálicos não ferrosos e minério de ferro & 0,005484 & 64 \\
\hline Fonte Elaça propra, resutados da pesquisa & &
\end{tabular}

Fonte: Elaboração própria, resultados da pesquisa.

$\mathrm{Na}$ tabela 7, demonstra-se os setores chave da mesorregião Sudeste, os quais possuem índice de ligação para frente e para trás superiores a um simultaneamente, são eles: abate e produtos; outros produtos alimentares; alimentação; pecuária inclusive apoio; outros equipamentos de transporte; produtos de madeira; outros serviços; construção; fabricação de químicos e resinas e elastômeros e fabricação de produtos de minerais não-metálicos. Ressaltando novamente que a economia da região está fortemente ligada às cadeias produtivas da pecuária e alimentos; produção de florestas e a indústria da construção naval e a construção.

Tabela 7 - Setores chave da mesorregião Sudeste

\begin{tabular}{l|l|l}
\hline Setores & Trás & Frente \\
\hline Abate e produtos & 1,6984 & 1,8507 \\
Outros produtos alimentares & 1,3854 & 2,1714 \\
Alimentação & 1,3284 & 1,0997 \\
Pecuária inclusive apoio & 1,2588 & 1,1672 \\
Outros equipamentos de transporte & 1,2009 & 1,0131 \\
Produtos de madeira - exclusive móveis & 1,2100 & 1,3756 \\
Outros serviços & 1,1333 & 1,3339 \\
Construção & 1,0742 & 1,6952 \\
Fabricação de químicos e resinas e elastômeros & 1,0704 & 1,0313 \\
Fabricação de produtos de minerais não-metálicos & 1,0609 & 1,1247 \\
\hline
\end{tabular}

Fonte: Elaboração própria, resultados da pesquisa. 
Buscando avaliar os impactos econômicos da duplicação do trecho sul da BR 116, realiza-se uma simulação para o período de obras, considerando que o valor atualizado da duplicação deve girar em torno de $\mathrm{R} \$ 1.285$ milhões, regionalizando o valor em km para a mesorregião Sudeste o valor se aproxima de 732,45 milhões. Partindo da equação (6), simula-se como choque de demanda para o setor de construção impacta na demanda intermediária setorial.

Os resultados de curto prazo dos choques de demanda no setor de construção oriundos da duplicação da BR 116 (trecho pertencente a mesorregião) indicam que um choque de $\mathrm{R} \$ \mathbf{7 3 2 , 4 5}$ milhões no setor de construção gera $\mathrm{R} \$$ 1.155,30 milhões na economia da região. Conforme demonstram os resultados da tabela 8, o maior impacto ocorre no setor de construção. Os setores de fabricação de produtos de minerais não-metálicos; produtos de madeira; comércio; produtos de metal; intermediação financeira; manutenção e instalação de máquinas e equipamentos e fabricação de máquinas e equipamentos são os principais fornecedores do setor de construção, por isso, sofrem impactos relativamente maiores que os demais setores.

Tabela 8 - Impacto do período de obras na produção em milhões de R\$ da duplicação da BR 116: Setores Selecionados

\begin{tabular}{l|c}
\hline Setor & $\begin{array}{c}\text { Valor em } \\
\text { milhões }\end{array}$ \\
\hline Construção & 928,6142 \\
Fabricação de produtos de minerais não-metálicos & 81,9765 \\
Produtos de madeira - exclusive móveis & 33,2557 \\
Comércio & 19,6873 \\
Produtos de metal - exclusive máquinas e equipamentos & 14,7391 \\
Intermediação financeira e seguros & 7,3963 \\
Manutenção, reparação e instalação de máq. e equip. & 7,0158 \\
Máquinas e equipamentos, exclusive manutenção e reparos & 6,6055 \\
Produção florestal, pesca e aquicultura & 5,8685 \\
Transporte de carga rodoviário & 5,6403 \\
Artigos de borracha e plástico & 3,7508 \\
Água, esgoto e gestão de resíduos & 3,3551 \\
Móveis e produtos das indústrias diversas & 3,0069 \\
Energia elétrica, gás natural e outras utilidades & 2,8078 \\
Outras atividades profissionais, cientificas e técnicas & 2,7737 \\
Alojamento & 1,9120 \\
Demais transporte de passageiros & 1,8456 \\
Armazenagem e correio & 1,4813 \\
Outros serviços & 1,3287 \\
Serviços de arquitetura, engenharia, testes e pesquisa e & \\
desenvolvimento & 1,3145 \\
Serviços imobiliários e aluguel & 1,2882 \\
Atividades jurídicas, contábeis e consultoria e sedes & 1,1453 \\
Fabricação de químicos e resinas e elastômeros & 1,0863 \\
\hline Fonte: &
\end{tabular}

Fonte: Elaboração própria, resultados da pesquisa. 
A partir das equações (6) e (7), foram mensurados os efeitos da redução das margens interregionais de $4 \%$ para o transporte rodoviário de cargas da mesorregião. Cabe mencionar que, os incrementos na produção e no valor adicionado se referem ao montante em valores monetários gerados pela redução das margens e não no valor total de produção e valor adicionado. O montante de redução de margens interregionais gira em torno de $\mathrm{R} \$ 47$ milhões para o modal rodoviário, são determinantes nesse valor a participação no modal na matriz estadual e o valor pago pela mesorregião com margens interregionais.

Os resultados para as margens de transporte rodoviário evidenciam que os setores de outros produtos alimentares; fabricação de automóveis, caminhões e ônibus; peças e acessórios para veículos automotores; fabricação de equipamentos eletrônicos e informática; artigos de borracha e plásticos; produtos farmoquímicos e farmacêuticos; máquinas e equipamentos; e agricultura, silvicultura e outros equipamentos para transporte sofreram os maiores incrementos na produção.

Por sua vez, as consequências relativas ao incremento no valor adicionado, tabela 9, retratam que a redução das margens gerou um aumento maior no valor adicionado de setores como outros produtos alimentares; agricultura, silvicultura; peças e acessórios para veículos automotores; produtos farmoquímicos e farmacêuticos; móveis e produtos das indústrias diversas; artigos de borracha e plástico; fabricação de equipamentos eletrônicos, informática; máquinas e equipamentos, exclusive manutenção e outros setores. Esse aumento, deriva da redução do custo de transporte e elevação da capacidade competitiva dos setores da região. 
Tabela 9 - Incremento setorial na produção e no valor adicionado oriundo da redução da margem de transporte rodoviário

\begin{tabular}{|c|c|c|}
\hline Setores & $\begin{array}{l}\text { Incremento no } \\
\text { VBP }\end{array}$ & $\begin{array}{l}\text { Incremento no } \\
\text { VAB }\end{array}$ \\
\hline Agricultura, silvicultura & $3,2638 \%$ & $17,3367 \%$ \\
\hline Produção florestal, pesca e aquicultura & $0,1383 \%$ & $0,6385 \%$ \\
\hline Extração de carvão mineral & $0,0012 \%$ & $0,0035 \%$ \\
\hline Extração de Petróleo e gás natural & $5,6877 \%$ & $0,0000 \%$ \\
\hline Abate e produtos & $0,4351 \%$ & $0,1935 \%$ \\
\hline Fabricação e refino de açúcar & $3,1022 \%$ & $0,0000 \%$ \\
\hline Outros produtos alimentares & $22,7679 \%$ & $20,6327 \%$ \\
\hline Fabricação de bebidas & $1,5191 \%$ & $1,4104 \%$ \\
\hline Produtos do fumo & $0,5487 \%$ & $0,1932 \%$ \\
\hline Têxteis & $1,7342 \%$ & $1,3526 \%$ \\
\hline Artigos do vestuário e acessórios & $0,1508 \%$ & $0,1584 \%$ \\
\hline Fabricação de calçados e couro & $0,5412 \%$ & $0,0600 \%$ \\
\hline Produtos de madeira - exclusive móveis & $0,9132 \%$ & $1,6071 \%$ \\
\hline Fabricação de celulose e produtos de papel & $2,6004 \%$ & $1,6702 \%$ \\
\hline Impressão e reprodução de gravações & $1,0667 \%$ & $2,3846 \%$ \\
\hline Refino de petróleo e coque & $2,2321 \%$ & $0,0955 \%$ \\
\hline Fabricação de biocombustíveis & $0,2459 \%$ & $0,0000 \%$ \\
\hline Fabricação de químicos e resinas e elastômeros & $1,3661 \%$ & $2,3762 \%$ \\
\hline Defensivos agrícolas, tintas e químicos diversos & $2,2025 \%$ & $1,5700 \%$ \\
\hline Perfumaria, higiene e limpeza & $2,8727 \%$ & $1,4358 \%$ \\
\hline Produtos farmoquimicos farmacêuticos & $4,3206 \%$ & $7,9469 \%$ \\
\hline Artigos de borracha e plástico & $4,4840 \%$ & $4,4993 \%$ \\
\hline Fabricação de aço e derivados & $1,1982 \%$ & $0,5935 \%$ \\
\hline Metalurgia de metais não-ferrosos & $2,2119 \%$ & $1,7014 \%$ \\
\hline $\begin{array}{l}\text { Produtos de metal - exclusive máquinas e } \\
\text { equipamentos }\end{array}$ & $0,2649 \%$ & $0,6742 \%$ \\
\hline $\begin{array}{l}\text { Fabricação de equipamentos eletrônicos, inf. } \\
\text { Fabricacão de equipamentos elétricos e }\end{array}$ & $5,1702 \%$ & $4,4007 \%$ \\
\hline eletrodomésticos & $1,2982 \%$ & $0,8694 \%$ \\
\hline $\begin{array}{l}\text { Máquinas e equipamentos, exclusive manutenção e } \\
\text { reparos }\end{array}$ & $3,9148 \%$ & $3,3651 \%$ \\
\hline Fabricação de automóveis, caminhões e ônibus & $10,2255 \%$ & $3,2919 \%$ \\
\hline Peças e acessórios para veículos automotores & $7,0923 \%$ & $11,9352 \%$ \\
\hline Outros equipamentos de transporte & $3,0299 \%$ & $1,3223 \%$ \\
\hline Móveis e produtos das indústrias diversas & $2,7462 \%$ & $4,9127 \%$ \\
\hline Edição, edição integrada e impressão & $0,6537 \%$ & $1,3688 \%$ \\
\hline Total & $100,0000 \%$ & $100,0000 \%$ \\
\hline
\end{tabular}

Fonte: Elaboração própria, resultados da pesquisa.

Em suma, os resultados para as margens interregionais de transporte rodoviário apontaram que os setores outros produtos alimentares; peças e acessórios para veículos automotores; fabricação de equipamentos eletrônicos e informática; artigos de borracha e plásticos; produtos farmoquímicos e 
farmacêuticos; máquinas e equipamentos; e agricultura, silvicultura e outros equipamentos para transporte sofreram os maiores incrementos na produção e no valor adicionado. Salienta-se que nos setores primários a redução das margens interregionais impactou mais fortemente no valor adicionado do que na produção. Esse resultado, reflete a estrutura econômica da região em estudo.

\section{Considerações finais}

Objetivo deste artigo foi estimar uma Matriz Insumo Produto para a mesorregião Sudeste do Rio Grande do Sul, quantificando a estrutura produtiva da região e os impactos econômicos da duplicação do trecho sul da BR 116. A partir da regionalização da matriz feita pelo método do Quociente Locacional e a decomposição das margens de transporte interregional, realizamos simulações de curto prazo com foco no período de realização das obras e no longo prazo, considerando a redução dos custos de transportes.

No tocante aos resultados dos multiplicadores de produção, percebemos que o perfil produtivo da mesorregião está relacionado as cadeias produtivas da pecuária e alimentos (abate e transformação), produção de florestas (plantação de pinus, produtos de madeira e resina) e a indústria da construção naval (outros equipamentos de transporte e fabricação de aço e derivados). Cabe mencionar que, a mesorregião Sudeste possui grande dependência na geração de valor adicionado das atividades ligadas aos segmentos comércio, construção, agropecuária e atividades de transporte e armazenagem em virtude do complexo portuário.

Partindo da definição de setores chave, a mesorregião apresentou como principais setores econômicos: abate e produtos; outros produtos alimentares; alimentação; pecuária inclusive apoio; outros equipamentos de transporte; produtos de madeira; outros serviços; construção; fabricação de químicos e resinas e elastômeros e fabricação de produtos de minerais não-metálicos. Ademais, os resultados indicam que a economia da região está fortemente ligada as cadeias produtivas da pecuária e alimentos; produção de florestas; indústria da construção naval e construção civil.

No tocante aos resultados da duplicação da BR 116, durante o período de realização das obras, o setor mais afetado foi o de construção e também sofrem impactos significativos os setores: fabricação de produtos de minerais não metálicos; produtos de madeira; comércio; produtos de metal; intermediação financeira; manutenção e instalação de máquinas e equipamentos e fabricação de máquinas e equipamentos, os quais são os principais fornecedores do setor de construção.

No longo prazo, a duplicação da rodovia reduz as margens de transporte em aproximadamente $\mathrm{R} \$ 47$ milhões por ano, sendo outros produtos alimentares; peças e acessórios para veículos automotores; fabricação de equipamentos eletrônicos e informática; artigos de borracha e plásticos; produtos farmoquímicos e farmacêuticos; máquinas e equipamentos; e agricultura, silvicultura e outros equipamentos para transporte, sendo os setores que sofrem os maiores incrementos na produção e no valor adicionado.

Em linhas gerais, a redução das margens do transporte rodoviário de cargas pode contribuir para o aumento da competividade da mesorregião e para a melhora 
nas relações de trocas entre as mesorregiões no Rio Grande do Sul. O término da duplicação da BR 116 deve melhorar os indicadores econômicos como PIB, exportações e emprego e reduzir o número de acidentes na rodovia, conforme indica a literatura empírica sobre melhorias em transporte. Ademais, segundo o Detran/RS (2016) os gastos financeiros (materiais, hospitalares e gastos com saúde) com acidentes na rodovia giram em torno de R\$ 50 milhões por ano, sem considerar a perda de vidas.

A elaboração de uma MIP para a mesorregião Sudeste e a avaliação de impactos econômicos da duplicação BR 116 foram as contribuições desse trabalho. A partir dos resultados apresentados, é possível esboçar políticas públicas de planejamento voltadas a mesorregião e ao setor de transporte, porém, tais resultados indicam tendências e levam em consideração aspectos teóricos e regionais, por isso, possuem limitações.

Nesse sentido, um aperfeiçoamento deste trabalho deve incorporar procedimentos como a desagregação do setor de agricultura e a implementação de um modelo de Equilíbrio Geral Computável (EGC) para o estado e/ou para a mesorregião. Tais procedimentos proporcionam uma gama maior de indicadores macroeconômicos, tais como, o PIB e seus componentes, emprego e produtividade dos fatores e, podem aprofundar as análises e suas implicações para a economia da região.

\section{REFERÊNCIAS}

ARAÚJO, M. P. DE; GUILHOTO, J. J. M. Infraestrutura de transporte e desenvolvimento regional: Uma abordagem de equilíbrio geral inter-regional. Teoria e Evidência Econômica, V. 14, n.31, p. 9-40, 2008.

BRENE, P. R. A; SESSO FILHO, U. A; COSTA, A. J. D; RANGEL, R. R. Estimativa da matriz de insumo-produto do município de São Bento do Sul no Estado de Santa Catarina. Revista Brasileira de Gestão e Desenvolvimento Regional. V. 7, n. 3, p. 250269, set-dez/2011.

BROCKER, J. Assessing spatial economic e ects of transport by CGE analysis: state of the art and possible extensions. Paper to be presented at the JFirst International ITEM Workshop", Montreal, Canada October 13, 2000.

CHRISTALLER, W. Central places in Southern Germany. New Jersey: Prentice-Hall, 1966.

CNT. Pesquisa da Confederação Nacional do Transporte sobre Rodovias, 2014. Disponível em: http://pesquisarodovias.cnt.org.br/Paginas/index.aspx. Acessado em $12 / 12 / 2014$.

FEE. Fundação de Economia e Estatística do RS. Dados sobre o Rio Grande do Sul por mesorregião. Disponível em: http://feedados.fee.tche.br/feedados/ Acesso em: 25/08/2017. 
FIGUEIREDO, M. G. F; BARROS, A. L. M; GUILHOTO, J. J. M. Relação econômica dos setores agrícolas do Estado do Mato Grosso com os demais setores pertencentes tanto ao Estado quanto ao restante do Brasil. Revista de Economia e Sociologia Rural. Rio de Janeiro, V. 43, n. 03, p. 557-575, 2005.

GUILHOTO, J. J. M. Input-Output Analysis: Theory an Foundations. Departamento de Economia. FEA-USP. Versão Revisada. 2011.

HADDAD, E. A. Retornos Crescentes, Custos de Transporte e Crescimento Regional. Tese de Doutorado (FACULDADE DE ECONOMIA, ADMINISTRAÇÃO E CONTABILIDADE DEPARTAMENTO DE ECONOMIA) - São Paulo: USP, 2004.

HIRSCHMAN, A. O. Estratégia do Desenvolvimento Econômico. Rio de Janeiro: Fundo de Cultura, 1961.

ISARD, W. Localization and Space Economy: A General Theory Relating to Industrial Location, Market Areas, Land Use, Trade and Urban Structure. Cambridge: MIT Press, 1956.

ISARD, W. Interregional and regional input-output analysis: a model of a spaceeconomy. Review of Economics and Statistics, Cambridge-Mass.: Elsevier, $\mathrm{n}$. 33, p. 319-328, 1951.

LEIVAS, P. H; FEIJÓ, F. T. Estrutura produtiva e multiplicadores de impacto inter setorial do Conselho Regional de Desenvolvimento da Região Sul (Corede Sul) do Rio Grande do Sul: uma análise de insumo-produto. Porto Alegre: Ensaios FEE, V. 35, n. 2, p. 521-554, dez. 2014.

LEONTIEF, W. Quantitative Input-Output Relations in the Economic Systems of the United Statesll. Review of Economics and Statistics, n.18, p. 105-25, 1936.

LÖSCH, A. The economics of location. Yale United Press: New Haven, 1954.

MILLER, R. E.; BLAIR, P. D. Input-output analysis: foundations and extensions. Cambridge: Cambridge University Press, 2009.

NUNES, P. A.; MELO, C. O. Estrutura Produtiva da Mesorregião Sudeste Paranaense com Abordagem Insumo-Produto. Revista Paranaense de Desenvolvimento. n.123, p. 179-212, 2012.

PEROBELLI, F. S; MATTOS, R. S; FARIA. W. R. Interações energéticas entre o Estado de Minas Gerais e o restante do Brasil: uma análise inter-regional de insumoproduto. Revista Economia Aplicada, V. 11, n. 1, p. 113-130, 2007.

PORSSE, A. A.; HADDAD, E. A.; RIBEIRO, E. P. Estimando uma matriz de insumoproduto inter-regional Rio Grande do Sul: restante do Brasil. São Paulo: Núcleo de 
Economia Regional e Urbana da USP: NEREUS2003, 2003. (Texto para discussão, 20). Disponível em: <http://www.econ.fea.usp.br/nereus>. Acesso em: 10/04/2016.

PORSSE, A. A.; PEIXOTO, F. C.; PALERMO, P. U. Matriz de Insumo-Produto interregional Rio Grande do Sul-restante do Brasil 2003: metodologia e resultados. Porto Alegre: FEE, (Textos Para Discussão FEE, n. 38), 2008.

PORSSE, A. A.; HADDAD, E. A.; RIBEIRO, E. P. Estimando uma matriz de insumo produto interregional Rio Grande do Sul-Restante do Brasil. In: ENCONTRO BRASILEIRO DE ESTUDOS REGIONAIS, Belo Horizonte. Anais... Belo Horizonte: Editor institucional, 2004.

RASMUSSEN, P. N. Studies in intersectoral relations. North Holland, Amsterdam, 1958.

REDDING, S.; VENABLES, A. Economic geography and international inequality. Journal of International Economics, Elsevier, V. 62, n. 1, p. 53-82, 2004.

RIBEIRO, L. C. S.; LEITE, A. P. V. ESTRUTURA ECONÔMICA DO ESTADO DE SERGIPE EM 2006: UMA CONTRIBUIÇÃO ATRAVÉS DA MATRIZ DE INSUMO-PRODUTO. Revista Econômica do Nordeste. V. 43, n. 4, p. 96-118, 2012.

RIBEIRO, L. C. S; MONTENEGRO, R. L. G; PEREIRA, R. M. ESTRUTURA ECONÔMICA E ENCADEAMENTOS SETORIAIS DE MINAS GERAIS: UMA CONTRIBUIÇÃO PARA AS POLÍTICAS DE PLANEJAMENTO. Revista Planejamento e Política Públicas, n. 41. jul./dez, p. 261-290, 2013.

ROBSON, E; DIXIT, V. A. Review of Computable General Equilibrium Modelling for Transport Appraisal. CONFERENCE OF AUSTRALIAN INSTITUTES OF TRANSPORT RESEARCH, 2015.

SECRETARIA DO PLANEJAMENTO, GESTÃO E PARTICIPAÇÃO CIDADÃ (SEPLAG). Situação dos transportes de carga no Rio Grande do Sul. 2013.

STONE, R. Input-output and demographic accounting: a tool for education planning. Minerva, V.4, n. 3, p.365-380, 1966.

TINBERGEN, J. Shaping the world economy: suggestions for an international economy policy. Nova York: Twentieth Century Fund, 1962.

TRUONG, T. P.; HENSHER, D. A. Linking discrete choice to continuous demand within the framework of a computable general equilibrium model. Transportation Research Part B, V. 46, p. 1177-1201, 2012.

VENABLES, A. Equilibrium locations of vertically linked industries. International Economic Review, V. 37, n. 2, p. 341-59, 1996. 
VON THÜNEN, J.H. 1826. The isolated state. Oxford: Pergamon Press, 1966.

WEBER, A. 1909. Theory of the location of industries. Chicago: Chicago University, 1969.

WIEBUSCH, F. C. Estrutura produtiva e multiplicadores de insumo produto do

COREDE Vale do Taquari. 2007. 88f. Dissertação (Mestrado em Economia) -

Pontifícia Universidade Católica do Rio Grande do Sul, Porto Alegre, 2007.

Rodrigo da Rocha Gonçalves. Doutor em Economia pela Pontifícia Universidade Católica do Rio Grande do Sul. Professor na Universidade Federal do Rio Grande. CEP 96201-900, Rio Grande/RS. rrochagoncalves@gmail.com

Gabrielito Menezes. Doutor em Economia Aplicada pela Universidade Federal do Rio Grande do Sul. Professor na Universidade Federal de Pelotas. CEP 96010-610, Pelotas/RS. gabrielitorm@gmail.com

Como citar: GONÇALVES, Rodrigo da Rocha; MENEZES, Gabrielito Rauter. Efeitos Econômicos da Duplicação da BR 116: uma análise para a Mesorregião Sudeste do Rio Grande do Sul. Redes (St. Cruz Sul, Online), Santa Cruz do Sul, v. 25, p. 1864-1889, nov. 2020. ISSN 1982-6745. doi:https://doi.org/10.17058/redes.v25i4.12813.

\section{CONTRIBUIÇÃO DE CADA AUTOR}

a. Fundamentação teórico-conceitual e problematização: Rodrigo da Rocha Gonçalves e Gabrielito Menezes.

b. Pesquisa de dados e análise estatística: Rodrigo da Rocha Gonçalves e Gabrielito Menezes.

c. Elaboração de figuras e tabelas: Rodrigo da Rocha Gonçalves e Gabrielito Menezes.

d. Fotos: não tem.

e. Elaboração e redação do texto: Rodrigo da Rocha Gonçalves e Gabrielito Menezes.

f. Seleção das referências bibliográficas: Rodrigo da Rocha Gonçalves e Gabrielito Menezes.

Fontes de financiamento: Sem financiamento por agência de fomento. 